\title{
Use of Satellite Photography in Mapping the Structure of Soil Cover in the Krasnoyarsk Forest-Steppe
}

\author{
Tatyana N. Demyanenko* and Valentina V. Chuprova \\ Krasnoyarsk State Agrarian University \\ 90 Mira, Krasnoyarsk, 660049, Russia
}

Received 07.02.2018, received in revised form 10.07.2018, accepted 04.10.2018

This article presents the results of detailization of a large-scale soil map of agricultural lands on the basis of high-resolution satellite images and ground-based studies. With the use of GIS technologies, a map of the structure of soil cover of a key section of the central part of the Krasnoyarsk forest-steppe and of Prieniseyskaya Siberia was compiled. Phototagons were obtained for the interpretation of images when mapping the soil cover of a watershed and slope surface.

Keywords: soil cartography, structure of soil cover, decryption keys, catena or toposequence.

Citation: Demyanenko T.N., Chuprova V.V. Use of satellite photography in mapping the structure of soil cover in the Krasnoyarsk forest-steppe, J. Sib. Fed. Univ. Eng. technol., 2019, 12(5), 519-525. DOI: 10.17516/1999-494X-0107.

\section{Использование космоснимков}

\section{при картографировании структуры почвенного покрова}

\section{в Красноярской лесостепи}

Т.Н. Демьяненко, В.В. Чупрова Красноярский государственный аграрный университет Россия, 660049, Красноярск, пр. Мира, 90

В статье представлены результаты детализации крупномасштабной почвенной карты сельскохозяйственных угодий на основе космических снимков высокого разрешения и наземных исследований. С использованием ГИС-технологий составлена карта структуры почвенного покрова ключевого участка центральной части Красноярской лесостепи Приенисейской Сибири. Получены фотоэталоны для дешифрирования снимков при картографировании почвенного покрова водораздельной и склоновой поверхностей.

(C) Siberian Federal University. All rights reserved

This work is licensed under a Creative Commons Attribution-NonCommercial 4.0 International License (CC BY-NC 4.0)

* Corresponding author E-mail address: t-demyanen@mail.ru, soil-valentina@yandex.ru 
Ключевые слова: почвенная картография, структура почвенного покрова, дешифровочные ключи, катена.

\section{Введение}

Одной из насущных проблем современного сельского хозяйства является экологизация земледелия, реализуемая в адаптивно-ландшафтных системах земледелия, главными принципами которых выступают экологическая целесообразность и экономическая эффективность [1]. Одно из условий разработки и создания систем - дифференциация территории на элементарные ареалы агроландшафта (ЭАА). Агроландшафт - это геосистема, выделяемая по совокупности ведущих агроэкологических факторов (определяющих применение тех или иных систем земледелия), функционирование которой происходит в пределах единой цепи миграции вещества и энергии. С точки зрения агроэкологической типологии земель агроландшафт соответствует агроэкологической группе земель. ЭАА - участок на элементе рельефа, ограниченный элементарной почвенной структурой (ЭПС), реже элементарным почвенным ареалом (ЭПА) при одинаковых геологических и микроклиматических условиях [2]. Таким образом, основой для выделения ЭАА служат единицы деления почвенного покрова. Согласно концепции В.М. Фридланда [3], структура почвенного покрова (СПП) - это его неоднородность, выявляющаяся обычно в виде смены относительно небольших ареалов почв внутрипочвенных зон, подзон, провинций. При формировании АгроГИС структуры почвенного покрова используются как матрицы, на которые накладываются другие агроэкологические характеристики. На их основе разрабатывается агроэкологическая группировка земель, в соответствии с которой проектируются адаптивно-ландшафтные системы земледелия [4].

Почва - специфический объект картографирования. Она невидима с поверхности и обнаруживается точечным опробованием, параллельно устанавливаются и анализируются почвенно-ландшафтные связи и результаты анализа экстраполируются на окружающую территорию. Факторами-индикаторами выступают рельеф, породы, растительность и данных дистанционного зондирования [5]. Во многих регионах разработаны эталоны фотоизображений, значительно облегчающие работу по выявлению СПП $[6,7]$. Для земледельческой зоны Красноярского края таких сведений пока нет.

Цель настоящего исследования - выявление неоднородностей почвенного покрова путем его детализации и типизация элементарных почвенных структур на территории центральной части Красноярской лесостепи.

\section{Методы исследования}

Объект исследования - сельскохозяйственные угодья учхоза Красноярского государственного аграрного университета «Миндерлинское», расположенного в Сухобузимском районе и в геоботаническом отношении приуроченного к Красноярской лесостепи.

Климат территории очень континентальный (коэффициент континентальности, рассчитанный по Иванову, 220) и семигумидный (полувлажный). По данным метеостанции Сухобузимское [8], среднегодовое количество осадков составляет 411 мм, максимальное их количество выпадает в июле и августе. Коэффициент увлажнения равен 0,81 и характеризует тип водного 
режима как периодически промывной. Гидротермический коэффициент по Селянинову 1,29, что соответствует достаточной увлажненности. Устойчивые активные температуры устанавливаются только 28 мая, таким образом, период активной вегетации составляет 108 дней. Снежный покров разрушается в III декаде апреля, но полностью поверхность почвы освобождается от снега лишь в середине мая.

Красноярская лесостепь расположена в пределах Чулымо-Енисейской денудационной равнины. В тектоническом отношении это относительно стабильный участок Кемчугской впадины $[9,10]$. Сложена территория песчаниками и алевролитами юрской системы, перекрытыми лессовидными и делювиальными суглинками и глинами. Волнистый денудационный рельеф территории представлен пологими (до $15^{\circ}$ ) склонами, верхние части которых формируются под воздействием плоскостного смыва, средние - совместным действием склоновых процессов и временных водотоков. Длительная сезонная мерзлота обуславливает формирование выраженного микрорельефа - суффозионно-просадочного на водоразделах и протяжинного на склонах.

В качестве основы нами использована почвенная карта территории учхоза, составленная в 1989 г. Росземпроектом института «Востсибгипрозем» г. Красноярска в масштабе 1:25000. Карта оцифрована средствами ГИС MapInfo (версия 10.5) в проекции WGS 84. Координатное пространство задано с помощью навигационной программы Sas.Planet. В электронной версии сохранена авторская систематика почв согласно Классификации 1977 г. [11]. Цифровой вариант карты опубликован ранее [12].

Площадь землепользования составляет 9500 га. Холмисто-увалистый рельеф территории учхоза обусловливает значительную комплексность почвенного покрова. Суммарная площадь однородных контуров занимает 28,9 \% территории.

Анализ карты показал, что в структуре почвенного покрова землепользования учхоза «Миндерлинское» значительную долю (21 \%) составляют мощные темно-серые оподзоленные почвы, образующие самостоятельные ареалы и сочетания с лугово-черноземными оподзоленными. Наибольшие абсолютные отметки являются территорией распространения серых оподзоленных почв, доля которых около 19 \% от общей площади хозяйства.

Черноземы выщелоченные занимают 29,6 \% от общей площади. В основном они сочетаются с обыкновенными среднегумусными и лугово-черноземными оподзоленными почвами. Площади обыкновенных черноземов равны 10,5 \% территории.

Остальная площадь занята полугидроморфно-подчиненными ЭПС.

Несмотря на крупный масштаб и более подробное содержание в отличие от предыдущих версий, данная карта не отражает неоднородности почвенного покрова, обусловленные выраженным микрорельефом территории, происхождение которого связано с криогенными явлениями. При отсутствии детальной топографической основы единственным способом картографирования территории служит прямое дешифрирование космических снимков высокого разрешения.

Ключевой участок для дешифрирования представляет собой катену 1600 м, заложенную на северном склоне междуречья рек Бузим и Миндерла в 2 км западнее пос. Борск $\left(98,88^{\circ}\right.$ в.Д., $56,4^{\circ}$ с.ш.). В работе проанализирована верхняя часть катены, включающая водораздельный и склоновый участки, занятые пашней.

$$
-521-
$$


Неоднородности почвенного покрова на пашне лучше всего прослеживаются на ранневесенних снимках с открытой поверхностью. Мы использовали спутниковую фотографию картографического online-сервиса «Яндекс.Карты», сделанную в этот период. В мае 2017 г. проведено детальное почвенное обследование участка методом дешифровочных ключей микрокатенным способом. Почвы систематизированы согласно современной классификации [13]. На основании всех имеющихся материалов создан векторный слой карты структуры почвенного покрова в MapInfo Professional 10.5.

\section{Результаты и их обсуждение}

По почвенной карте 1989 г. исследуемый участок находится в пределах контура среднеи малогумусных маломощных обыкновенных черноземов. Микрорельеф водораздельного участка грядово-протяжинный, протяжины закрытого типа, происхождение которых связано с суффозионными просадками. Общий уклон поверхности составляет 0.3-1.7 градуса. Полевые исследования выявили различия почв на типовом уровне (рис. 1). Темные участки на снимке соответствуют ареалам черноземов глинисто-иллювиальных среднемощных (Чги”) (черноземы выщелоченные по классификации 1977 г.). Мощность гумусового горизонта варьирует от 57 до 80 см, присутствие карбонатных солей в профиле не обнаруживается. Они приурочены к протяжинам. На дне протяжин (наиболее темные пятна на снимке) обнаружены небольшие, около 200 м² $^{2}$ ареалы черноземов глинисто-иллювиальных среднемощных с погребенными гумусовыми горизонтами (Чги”+2г) мощностью 25-40 см. Их происхождение, возможно, связано с раскорчевкой древесных колков, проводимой при так называемой оптимизации структуры посевных площадей хозяйства в 70-е гг. прошлого века. Следствием такого вмешательства становится усиление эрозии и далее увеличение неоднородности почвенного покрова, проявляющегося в постепенной «сработке» гумусового горизонта на микроповышениях. Основной фон - постепенные переходы серых и светло-серых тонов - представляет собой ЭПС (пятнистость) из черноземов криогенно-мицеллярных мелких, вскипающих в нижней части гумусового горизонта мощностью $17-20$ cм, с ровной границей и ясным переходом между гумусовым и нижележащим горизонтом, и черноземов глинисто-иллювиальных маломощных (30-45 см),

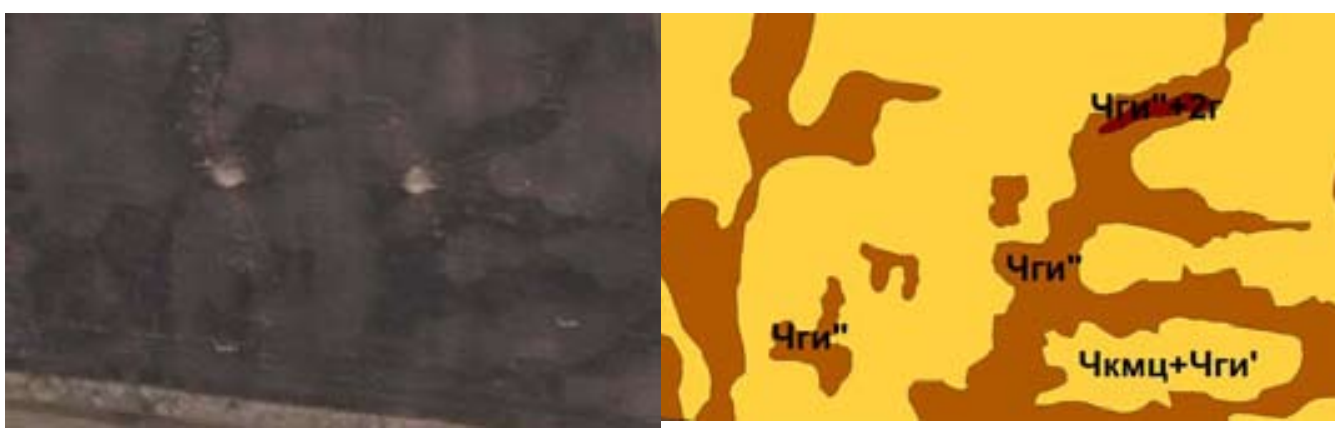

Рис. 1. Фрагмент космического снимка и карты структуры почвенного покрова водораздельной части катены

Fig. 1. Fragment of the satellite image and map of the structure of the soil cover of the watershed part of the catena 

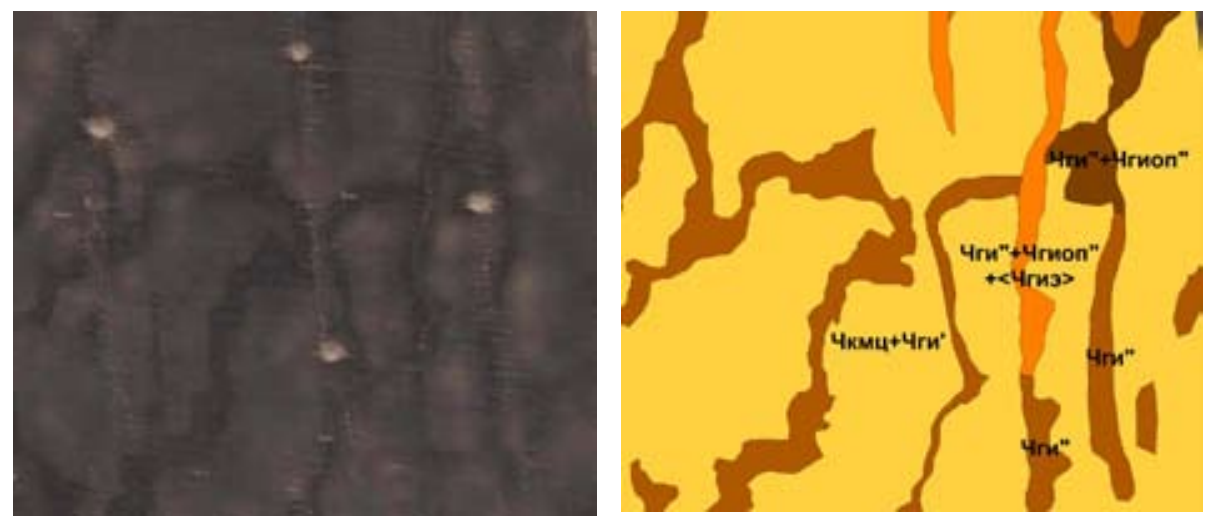

Fig. 2. Фрагмент космического снимка и карты структуры почвенного покрова склоновой части катены

Fig. 2. Fragment of the satellite image and map of the structure of the soil cover of the slope of the catena

вскипающих ниже 70 см (Чкмц+Чги'). Светлые круглые пятна на снимке не имеют отношения к почвам и, по всей видимости, есть очаги незапаханной соломы.

Склон характеризуется усилением крутизны (0.9-4 градуса) и почвенной неоднородности с заметным участием эродированных компонентов. Протяжины приобретают линейные формы (рис. 2). В зависимости от микрорельефа они либо полузамкнуты и являются контурами все тех же черноземов глинисто-иллювиальных среднемощных, либо представлены открытыми линейными формами с белесоватой полосой-протяжинами с эрозионными промоинами на дне. Эти контуры формируют пятнистости из черноземов глинисто-иллювиальных типичных и оподзоленных среднемощных и глинисто-иллювиальных эродированных (смытых) (до 10 \% от площади контура) (Чги”+Чгиоп”+<Чгиэ>).

Правая верхняя часть фрагмента снимка приходится на край крупной западины. Контур пятна становится изометричным и представляет пятнистость тех же среднемощных черноземов глинисто-иллювиальных типичных и оподзоленных, но без признаков смытости (Чги"+Чгиоп”).

Отметим, что полученные результаты картографирования не окончательны. Они требуют, во-первых, проверки на воспроизводимость в схожих почвенно-экологических условиях, а вовторых, на оценку разных видов неопределенностей, возникающих при детальном цифровом почвенном картировании. Например, неопределенности, связанные с оценкой связей почвенных свойств и морфометрических характеристик рельефа, оглеения и показателей эрозионного потенциала.

Карты структуры почвенного покрова катены позволили выделить агроэкологические группы земель. Водораздельная часть катены соответствует плакорным землям, склоновая эрозионным, где главным лимитирующим плодородие фактором служит смытость и наличие промоин, появляющихся в результате плоскостного смыва. Это указывает на корректировку характера использования таких массивов. Таким образом, подобные карты могут использоваться для принятия управленческих решений на уровне хозяйств и административных районов. Предлагается сосредоточить усилия на создании обновленных почвенных карт в среде ГИС, спутниковых технологий и цифровых моделей рельефа на каждое хозяйство (первый этап) и

$$
-523-
$$


составлении почвенных карт административных районов с обязательным показом границ разных землепользователей, входящих в район (второй этап). Сопоставление и анализ структуры почвенного покрова повысит их информативность и возможности при мониторинговых исследованиях и практическом использовании.

\section{Заключение}

На исследуемой территории выделено два типа почвенных структур: зональная (водораздельная часть) и эрозионно-зональная (склоновая часть). На территории Красноярской лесостепи подобных исследований структуры почвенного покрова до настоящего времени не проводилось. Таким образом, использование космоснимков высокого разрешения обеспечивает получение корректных характеристик почвенного покрова, ускоряет анализ и обновление информации и является приемлемым инструментом для принятия решений при планировании использования агроэкологических ресурсов территории.

\section{Список литературы}

[1] Кирюшин В.И. Оценка качества земель и плодородия почв для формирования систем земледелия и агротехнологий. Почвоведение, 2007, (7), 273-880 [Kiryushin V.I. Assessment of soil quality and soil fertility for the formation of systems of agriculture and agro-technologies. Soil science, 2007, (7), 273-880 (in Russian)]

[2] Кирюшин В.И. Теория адаптивно-ландшафтного земледелия и проектирование агроландшафтов. М.: КолосС, 2011. 443 с. [Kiryushin V.I. Theory of adaptive-landscape agriculture and the design of agro landscapes. M.: KolosS, 2011. 443 p. (in Russian)]

[3] Фридланд В.М. Структуры почвенного покрова мира. М.: Мысль, 1984. 235 с. [Fridland V.M. The structure of soil cover of the world. M.: Mysl', 1984. 235 p. (in Russian)]

[4] Агроэкологическая оценка земель, проектирование адаптивно-ландшафтных систем земледелия и агротехнологий. М.: ФГНУ «Росинформагротех», 2005. 784 с. [Agroecological assessment of lands, design of adaptive-landscape systems of agriculture and agro-technologies. M.: FGNU “Rosinformagrotech", 2005. 784 p. (in Russian)]

[5] Сорокина Н.П., Козлов Д.Н. Опыт цифрового картографирования структуры почвенного покрова. Почвоведение, 2009, (2), 198-210. [Sorokina N.P., Kozlov D.N. The experience of digital mapping of the structure of soil cover. Soil science, 2009, (2), 198-210 (in Russian)]

[6] Сорокина Н.П. Методология составления крупномасштабных агроэкологически ориентированных почвенных карт. М., 2006. 159 с. [Sorokina N.P. Methodology for compiling largescale agroecologically oriented soil maps. M., 2006. 159 p. (in Russian)]

[7] Курьянович М.Ф., Черныш А.Ф., Шалькевич Ф.Е. Эффективность использования материалов дистанционных съемок при обновлении почвенных карт. Почвоведение и агрохимия, Минск, 2015, 2(55), 18-30. [Kuryanovich M.F., Chernysh A.F., Shalkevich F.E. Efficient use of materials of remote sensin to update soil maps. Soil science and Agrochemistry, Minsk, 2015, 2(55), 18-30 (in Russian)]

[8] Архив погоды в Сухобузимском [Электронный ресурс] - Режим доступа: https://rp5.ru/ Архив_погоды_в_Сухобузимском [Weather archive in Sukhobuzimskoye [Electronic resourse] Access: https://rp5.ru/Weather_archive_in_Sukhobuzimskoye] 
[9] Карта четвертичных образований. Лист О-46-XXXIII, масштаб 1:200,000, второе издание [Электронный ресурс] - Режим доступа: http:/geolkarta.ru/list_200.php?idlist=O-46XXXIII\&idlist_d=Q\&gen=2\&g=1_[Map of Quaternary Formations. Sheet O-46-XXXIII, scale 1: 200,000, second edition [Electronic resourse] - Access: http://geolkarta.ru/list_200.php?idlist=O-46XXXIII\&idlist_d=Q\&gen $=2 \& \mathrm{~g}=1]$

[10] Геологическая карта. Лист O-46-XXXIII, масштаб 1:200 000, второе издание [Электронный ресурс] - Режим доступа: http://geolkarta.ru/list_200.php?idlist=O-46-XXXIII\&idlist_ $\mathrm{d}=$ G\&gen=2\&g=1_[Geological map. Sheet O-46-XXXIII, scale 1: 200,000, second edition [Electronic resourse] - Access: http://geolkarta.ru/list_200.php?idlist=O-46-XXXIII\&idlist_d=G\&gen=2\&g=1]

[11] Егоров В.В., Фридланд В.М., Иванова Е.Н. Классификаџия и диагностика почв СССР. М.: Колос, 1977. 221 с. [Egorov V.V., Fridland V.M., Ivanova E.N. Classification and diagnostics of soils of the USSR. M.: Kolos, 1977. 221 p. (in Russian)]

[12] Чупрова В.В., Демьяненко Т.Н., Жуков 3.С., Бабиченко Ю.В. Оценка плодородия почв и почвенных комбинаций пахотных земель Красноярской лесостепи. Почвоведение и агрохимия, Минск, 2015, 2(55), 47-56 [Chuprova V.V., Demyanenko T.N., Zhukov Z.C., Babichenko Yu.V. Evaluation of soil and soil combination fertility of croplands in Krasnoyarsk forest-steppe. Soil science and Agrochemistry, Minsk, 2015, 2(55), 47-56 (in Russian)]

[13] Шишов Л.Л., Тонконогов В.Д. и др. Классификаиия и диагностика почв России. Смоленск: Ойкумена, 2004. 342 c. [Shishov L.L., Tonkonogov V.D. Classification and diagnostics of soils in Russia. Smolensk: Oykumena, 2004. 342 p. (in Russian)] 